\title{
A sensitive lead titanate nano-structured sensor for electrochemical determination of pentoxifylline drug in real samples
}

\author{
Asma Khoobi $^{1,2} \cdot$ Abdol Mohammad Attaran $^{2} \cdot$ Masoud Yousofi $^{2} \cdot$ Morteza Enhessari $^{3}$
}

Received: 15 November 2018 / Accepted: 11 January 2019 / Published online: 21 January 2019

(c) The Author(s) 2019

\section{Abstract}

In the present study, lead titanate nano-sized powders were synthesized using citric acid gel method. The nanopowders were characterized using X-ray diffraction (XRD) and scanning electron microscopy (SEM). Then, a nanocomposite system based on lead titanate nanopowders and carbon paste electrode (CPE) was designed and applied for determination of pentoxifylline (PTX). The prepared nanostructured electrode exhibited voltammetric responses with high sensitivity and selectivity for PTX and a detection limit of $2.1 \mathrm{nM}$ was achieved. Finally, the proposed method was used for analysis of PTX in environmental and biological samples with satisfactory results.

\section{Graphical abstract}

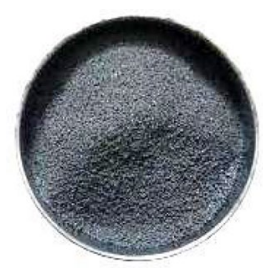

Graphite Powder

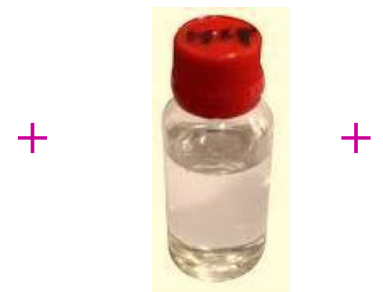

Paraffin Oil

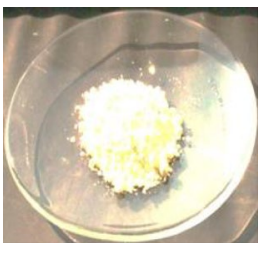

$\mathrm{PbTiO}_{3}$ nanoparticles

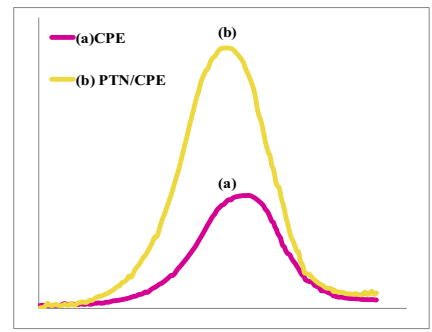

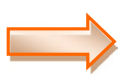

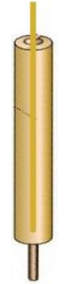

PTN/CPE

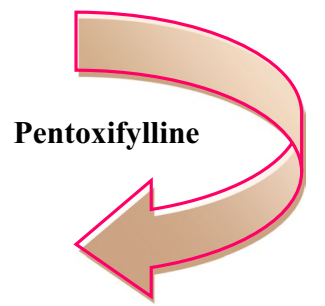

Keywords $\mathrm{PbTiO}_{3}$ nanopowders $\cdot$ Electrocatalytic detection $\cdot$ Pentoxifylline $\cdot$ Biological analysis

\section{Introduction}

Nanostructured materials, because of their important characteristics have been the focus of serious interest for the last decade world-wide. In this field most of the novel and remarkable properties appear when the particle size ranges asma.khoobi@gmail.com

Extended author information available on the last page of the article

exist below $100 \mathrm{~nm}[1,2]$. Ferroelectric compounds are a 
group of materials that possess low dielectric loss, high dielectric constants, high electrical resistivity and suitable electrooptical and electromechanical activates [3]. Ferroelectric materials that have perovskite structure $\left(\mathrm{ABO}_{3}\right)$, such as lead titanate $\left(\mathrm{PbTiO}_{3}\right)$ and barium titanate $\left(\mathrm{BaTiO}_{3}\right)$, are the most investigated ferroelectric oxide compounds due to their versatile characteristics for application in actuators, thin film capacitors, pyroelectric sensors and nonlinear optics. The materials with nano-sized dimensions have established significant research attention because of the unconventional physical and chemical behaviour at the nanoscale dimensions $[4,5] . \mathrm{PbTiO}_{3}$ is usually used in numerous electronic devices due to a high pyroelectric coefficient and low permittivity $[6,7]$. Some methods have been reported for preparation of $\mathrm{PbTiO}_{3}$, such as sol-gel method [8], hydrothermal synthesis [9], dip-pennanolithography [10] and liquid-solid-solution route [11]. It is known that chemical synthesis routes can be provide precise composition, high chemical purity, uniform microstructures and without high formation temperature of the perovskite phase based on molecular scale mixing in the preparation of the precursor. The sol-gel method is a usually applied chemical route for preparation of homogeneous large area thin films and uniform powders in micrometer, sub-micrometer or nanometer scales [12, 13].

Pentoxifylline (PTX) a tri-substituted xanthine derivative is a hemorheologic agent applied for the treatment of peripheral arterial disease and intermittent claudication. The drug improves blood flow by peripheral circulation via reducing blood viscosity, inhibiting platelet aggregation, improving erythrocyte flexibility, and decreasing fibrinogen concentration [14]. Beside the well-known hemorheological properties, it has been recognized to exert a broad range of immunological activities [15]. The compound also reduces leucocyte-endothelium interaction and shows a therapeutic effect in inhibiting ischemia reperfusion injury in microsurgical processes [16]. PTX can be prevented from strokes and used in managing sickle cell disease and increases blood flow to the brain [17]. Several methods for determination of PTX have been used, containing spectrophotometry [18], high performance liquid chromatography [14], gas chromatography [19], thin layer chromatography [20], and electrochemistry [21]. Some of the methods suffer from problems such as complexity, time consuming and need expensive instrumentation along with sample preparation. Among the various methods reported for PTX determination, electrochemistry technique is often favorable method because of their high sensitivity, selectivity, rapid detection and free of sample preparation steps. Electrochemical techniques that use chemically modified electrodes are usually important methods in medicine and biotechnology, environmental monitoring and industrial process control [22].

In the present study, a sol-gel method based on a metalcitrate system was used for synthesis of nano-sized $\mathrm{PbTiO}_{3}$.
Then, a sensitive and simple $\mathrm{PbTiO}_{3}$ nanoparticles modified carbon paste electrode (PTN/CPE) was designed for determination of PTX. Primary investigation about the formation of the nanoparticles and modified electrode were perused. Then, analysis of PTX at the surface of the nanostructured electrode was performed by electrochemical methods.

\section{Experimental}

\section{Materials}

All solutions were freshly prepared by deionized water and chemicals used were of analytical grade. Citric acid, tetra-n-butyl titanate, $\mathrm{H}_{2} \mathrm{O}_{2}, \mathrm{~Pb}\left(\mathrm{NO}_{3}\right)_{2} \cdot 6 \mathrm{H}_{2} \mathrm{O}$, ammonia solution, PTX, carbon graphite powder, paraffin oil and other chemicals were purchased from Merck and used without any further purification. Stock solutions of $0.2 \mathrm{M} \mathrm{H}_{3} \mathrm{PO}_{4}$, $\mathrm{CH}_{3} \mathrm{COOH}, \mathrm{H}_{3} \mathrm{BO}_{3}$ and a saturated solution of sodium hydroxide were used for preparation of $0.2 \mathrm{M}$ Britton-Robinson (B-R) buffer.

\section{Preparation of $\mathrm{PbTiO}_{3}$ nanostructures and working electrodes}

For synthesis of $\mathrm{PbTiO}_{3}$ nano-sized powders, tetra-n-butyl titanate was added to stirred deionized water and the precipitation was observed. Then, the precipitate was filtered and washed with deionized water. An appropriate of citric acid and $\mathrm{H}_{2} \mathrm{O}_{2}$ both in a 2:1 molar ratio against Ti(n-0C4H9) added and then, the solution became viscous and maroon in color. The $\mathrm{pH}$ value of the solution was adjusted to 6.0 by ammonia solution. For preparation of a water-soluble precursor for $\mathrm{Ti}(\mathrm{IV})$ continuous stirring and refluxing at $60{ }^{\circ} \mathrm{C}$ was performed. Then, stoichiometric amount of $\mathrm{Pb}\left(\mathrm{NO}_{3}\right)_{2}$ was dissolved in $5.0 \mathrm{M}$ citric acid solution with $\mathrm{pH}$ of 6.0 (adjusted by ammonia) and then, the $\mathrm{Pb}$ (II) precursor was mixed with the $\mathrm{Ti}(\mathrm{IV})$ precursor. The above mixture was refluxed at $60{ }^{\circ} \mathrm{C}$ for $2 \mathrm{~h}$ with continuous stirring. After drying in a furnace at $60^{\circ} \mathrm{C}$ for $24 \mathrm{~h}$ a porous citreous resin was formed. Then, the solid resin precursors were calcined at $500{ }^{\circ} \mathrm{C}$ and $550{ }^{\circ} \mathrm{C}$ for $2 \mathrm{~h}$ to obtain the $\mathrm{PbTiO}_{3}$ nanopowders (Scheme 1).

At the next step, the carbon paste electrode (CPE) was prepared by hand-mixing $0.50 \mathrm{~g}$ graphite powder with about $0.2 \mathrm{~mL}$ of paraffin oil in a pestle and mortar. For preparation of the modified electrode, appropriate amount of $\mathrm{PbTiO}_{3}$ nanopowders calcined at $550{ }^{\circ} \mathrm{C}$ (in proportions of 2, 4, 6, 8, and $10 \%$, w/w of $\mathrm{PbTiO}_{3}$ to graphite powder) was dispersed in $5.0 \mathrm{~mL}$ deionized water by an ultrasound bath and then mixed into graphite powder. After vaporizing water, about $0.2 \mathrm{~mL}$ of paraffin oil was added to the above mixture. 


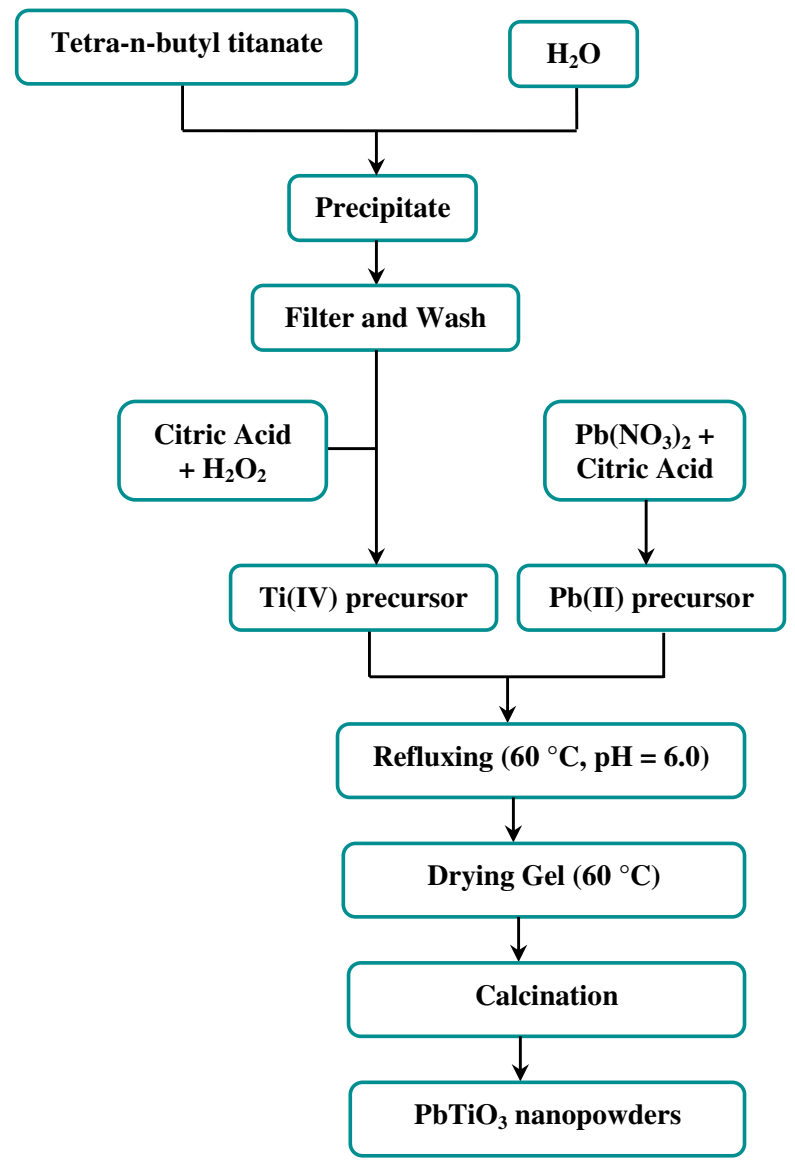

Scheme 1 Schematic diagram for the synthesis of $\mathrm{PbTiO}_{3}$ nanostructures

\section{Apparatus}

The X-ray diffraction (XRD) patterns of the nanopowders were recorded by a Model PI TS 3003 of SEIFERT diffractometer using $\mathrm{Cu} \mathrm{K} \alpha$ radiation $(k=1.5418 \AA$ ) to examine the crystallization and structural properties of $\mathrm{PbTiO}_{3}$ nanopowders. Scanning electron microscopy (SEM) micrographs were obtained using a KYKY-EM3200. Electrochemical experiments were carried out by an Autolab potentiostat-galvanostat PGSTAT 35 (Eco Chemie Utrecht, Netherlands), equipped with NOVA 1.6 software. The electrochemical cell was equipped with a three-electrode system containing a modified carbon paste, a platinum wire (Metrohm, Switzer-land) and an $\mathrm{Ag} / \mathrm{AgCl} / \mathrm{KCl}$ (3.0 M) (Metrohm, Switzerland) as the working, counter and reference electrodes, respectively. A digital $\mathrm{pH}$ meter (Metrohm model 691) was applied for preparation of buffer that served as a supporting electrolyte in the electrochemical analysis. An ultrasound bath (Bandelin Sonorex, Germany) at a constant frequency $(35 \mathrm{kHz})$ was applied for preparing the modified nanostructured electrodes. An ultra-pure water system (smart 2 pure, TKA, Germany) was used for preparation of deionized water. All electrochemical experiments were performed at $25^{\circ} \mathrm{C}$.

\section{Results and discussion}

\section{Structural and surface analysis}

The structural studies of the samples was investigated using XRD pattern of the $\mathrm{PbTiO}_{3}$ nanopowders calcined at $500{ }^{\circ} \mathrm{C}$ and $550{ }^{\circ} \mathrm{C}$. As can be observed in Fig. 1 , at $500{ }^{\circ} \mathrm{C}$, the crystallization of tetragonal phase took place along with impurity phase [23]. But, at $550{ }^{\circ} \mathrm{C}$ all peaks can be attributed to the $\mathrm{PbTiO}_{3}$ crystals with a tetragonal structure without any impurity peak. The crystallite size $(t)$ of the $\mathrm{PbTiO}_{3}$ nanopowders calcined at the two temperatures was achieved by the Scherrer's equation (Eq. 1):

$t=0.9 \lambda / \beta \cos \theta$

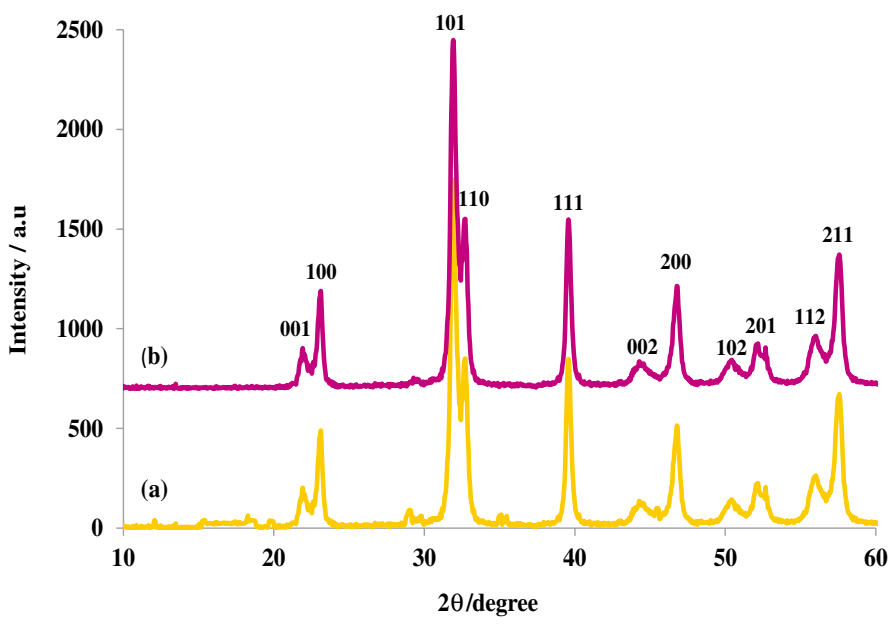

Fig. 1 XRD pattern of $\mathrm{PbTiO}_{3}$ nanostructures calcined at $\mathbf{a}$ $500{ }^{\circ} \mathrm{C}$ and $\mathbf{b} 550{ }^{\circ} \mathrm{C}$ for $2 \mathrm{~h}$ 
where $\lambda, \beta$ and $\theta$ are wavelength of radiation, the peak width at its half maximum intensity and diffraction angle, respectively. Based on the data the crystallite size of $\mathrm{PbTiO}_{3}$ nanostructures at $500{ }^{\circ} \mathrm{C}$ and $550{ }^{\circ} \mathrm{C}$ were obtained 30.3 and $39.2 \mathrm{~nm}$, respectively.

The morphologies and particle sizes of the $\mathrm{PbTiO}_{3}$ nanopowders calcined at $550{ }^{\circ} \mathrm{C}$ have been investigated using SEM micrographs. Fig 2 shows that $\mathrm{PbTiO}_{3}$ nanopowders with the diameter in the range of $37 \mathrm{~nm}$ to $60 \mathrm{~nm}$ are uniformly distributed.

Also for investigation of the CPE modification process SEM was used. Figure 3 compares the morphological features of (A) CPE and (B) PTN/CPE. SEM was used to estimate the surface characteristics of $\mathrm{PbTiO}_{3}$ nanoparticles at the surface of CPE. The SEM micrograph of CPE showed irregularly shaped particles that appeared to remain isolated (Fig. 3a). Whereas, the SEM micrograph of PTN/ CPE (Fig. 3b), demonstrates dissimilar morphology than the unmodified electrode. The micrographs indicate that the

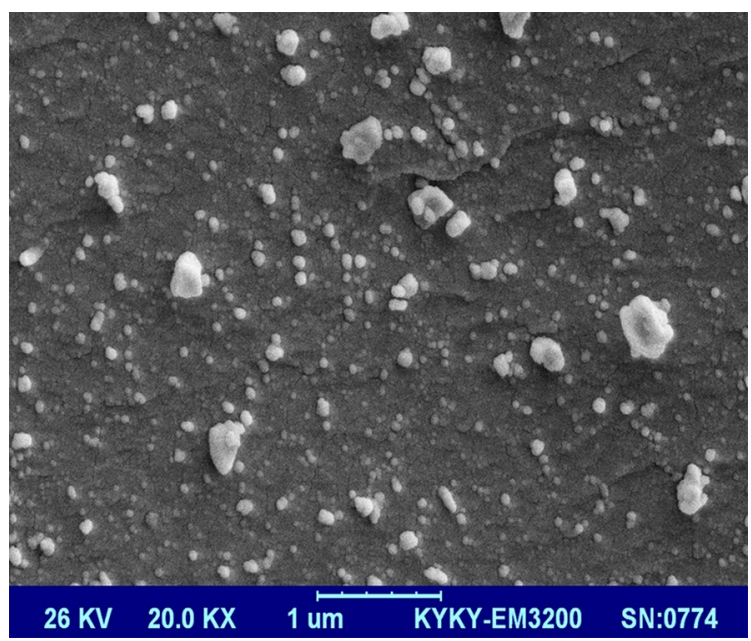

Fig. 2 SEM micrographs of $\mathrm{PbTiO}_{3}$ nanostructures calcined at $550{ }^{\circ} \mathrm{C}$ for $2 \mathrm{~h}$ modification of the CPE surface with $\mathrm{PbTiO}_{3}$ nanoparticles has been well accomplished.

\section{Electrochemical properties of the PTN/CPE}

For investigation of the catalytic activity of the PTN/CPE, differential pulse voltammetry (DPV) technique was used. The differential pulse voltammograms of PTX at the surface of the CPE and PTN/CPE were recorded (Fig. 4). As can be seen, PTN/CPE shows a well-defined oxidation peak with magnification of about 3.0 times greater than the CPE. An enhancement in current response by the nanostructured modified electrode is clear evidence of the catalytic effect of $\mathrm{PbTiO}_{3}$ nanostructures on the oxidation of PTX.

\section{Optimization studies}

DPV data in Fig. 4 approved that the PTN/CPE shows a higher sensitivity for PTX compared to the CPE. But, a set of experiments were performed at the surface of PTN/CPE to achieve the optimum experimental factors for achieving the best sensitivity for PTX.

\section{Effect of $\mathrm{pH}$}

The $\mathrm{pH}$ value is a key parameter in electrochemical studies in $\mathrm{pH}$-dependent systems. Therefore, the effect of $\mathrm{pH}$ was studied by DPV in $0.2 \mathrm{M}$ B-R buffer with different $\mathrm{pH}$ values (7.0, 7.5, 8.0, 8.5, and 9.0) containing PTX. As it is shown in Fig. 5a, with changing in $\mathrm{pH}$ of the supporting electrolyte both the peak current and peak potential of PTX is shifted. Thus, the oxidation reaction of PTX at the PTN/CPE is a $\mathrm{pH}$-dependent system. Additionally, the highest oxidation peak current for PTX was obtained at pH 7.5 (Fig. 5b). Thus, $\mathrm{pH} 7.5$ was selected for the sensitive determination of PTX.
Fig. 3 SEM micrographs of a CPE and $\mathbf{b} \mathrm{PTN} / \mathrm{CPE}$
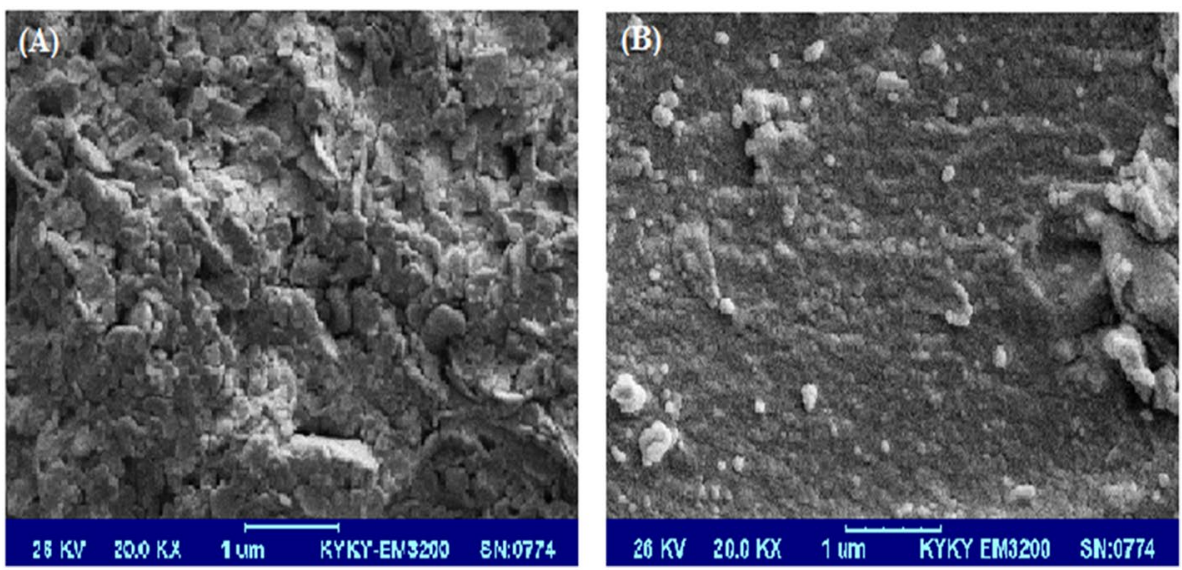
Fig. 4 Differential pulse voltammograms of PTX at the surface of a CPE and b PTN/ $\mathrm{CPE}$
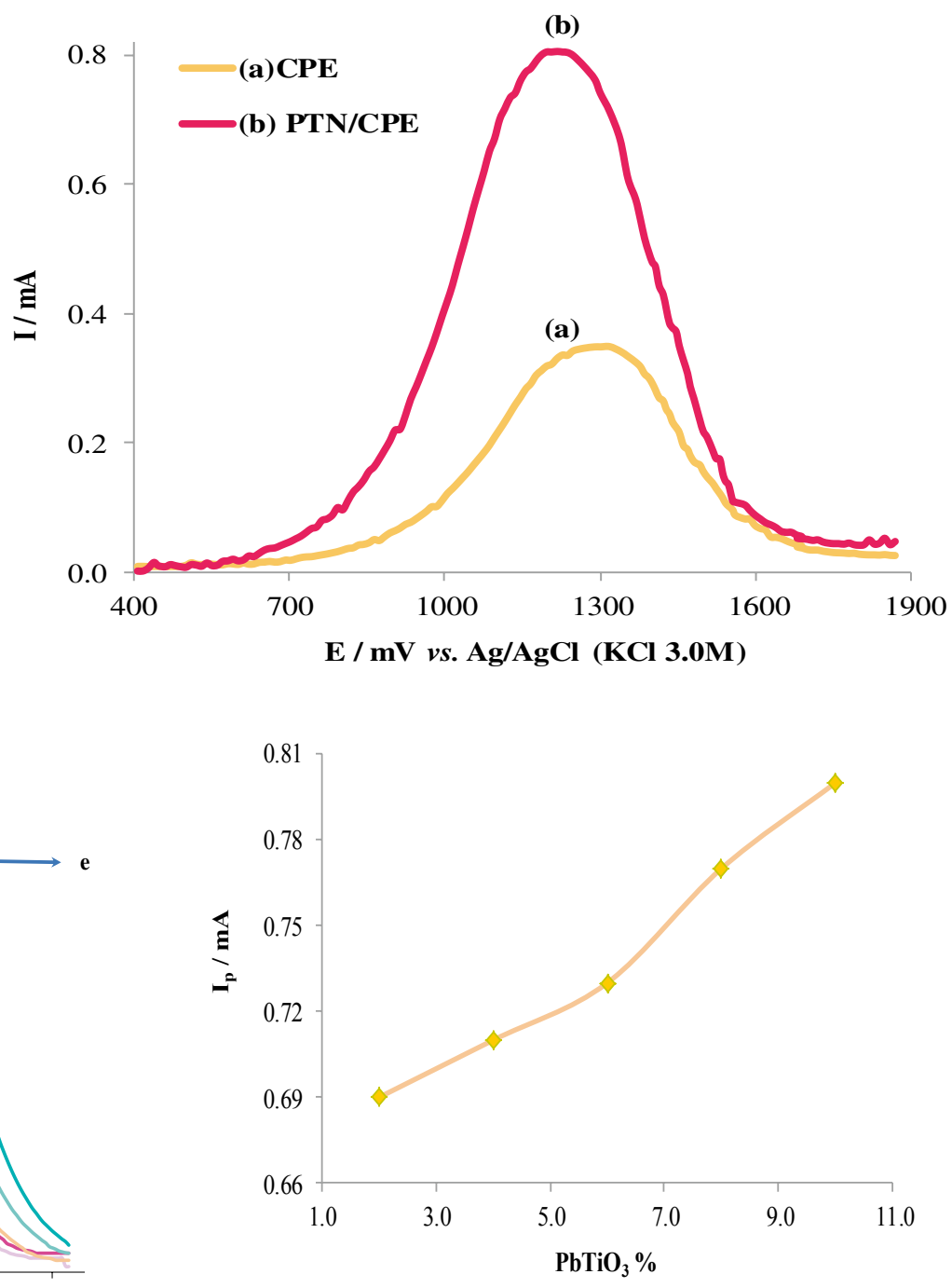

Fig. 6 Plot of $\left(I_{\mathrm{pa}}, \mathrm{mA}\right)$ of PTX with different quantities of $\mathrm{PbTiO}_{3}$ nanoparticles

\section{Effect of instrumental parameters}

For achieving the best sensitivity for detection of PTX both chemical (pH and $\mathrm{PbTiO}_{3}$ amount) and instrumental parameters should be optimized. Therefore, the effect of scan rate $(v)$ and modulation amplitude as instrumental parameters on the oxidation peak current of PTX was studied. So, the experiments were performed at different scan rates from 10.0 to $50.0 \mathrm{mV} \mathrm{s}^{-1}$ (Fig. 7) at the surface of PTN/CPE. The results showed by increasing the scan rate, the heights of oxidation peak were increased. Therefore, scan rate was adjusted on $50.0 \mathrm{mV} \mathrm{s}^{-1}$ for determination of PTX.

Additionally, modulation amplitude effect on the electrochemical behaviour of PTX was studied. Figure 8 shows the oxidation peak current of PTX changes with changing in modulation amplitude from 0.1 to $0.5 \mathrm{~V}$. The results shows modified nanostructured electrode. 


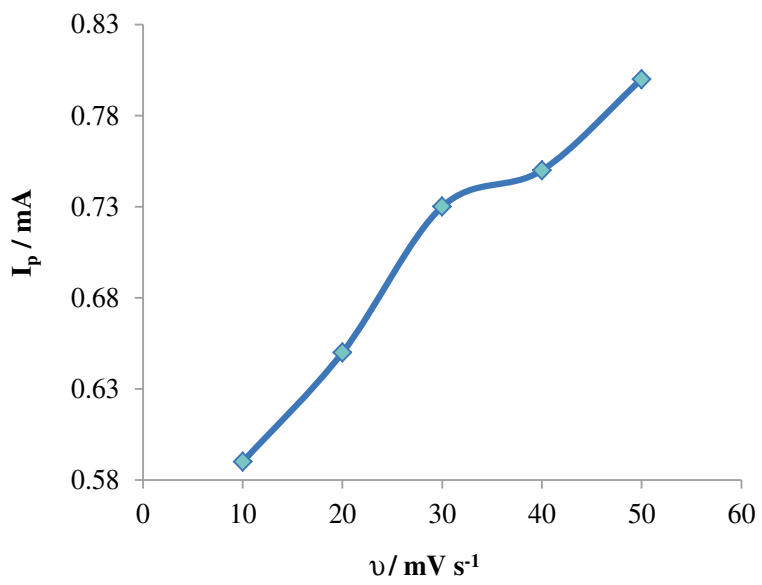

Fig. 7 Plot of $\left(I_{\mathrm{pa}}, \mathrm{mA}\right)$ of PTX at the surface of PTN/CPE in different scan rates

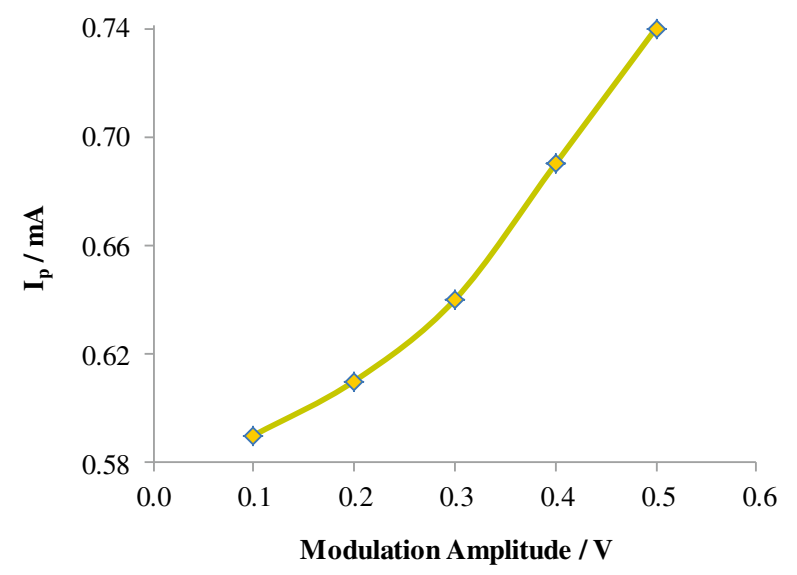

Fig. 8 Plot of $\left(I_{\mathrm{pa}}, \mathrm{mA}\right)$ of PTX at the surface of PTN/CPE in different modulation amplitudes

maximum of peak current obtains when modulation amplitude was adjusted on $0.3 \mathrm{~V}$.

\section{Determination of PTX at the surface of PTN/CPE}

The main purpose of the work is designing a high sensitive method for determination of PTX. For achieving the best response of PTX at the surface of PTN/CPE, all effective factors on the oxidation peak current of the analyte were adjusted on the optimized conditions. Therefore, the voltammograms were recorded in the presence of B-R buffer (pH 7.5), $10 \%$ of $\mathrm{PbTiO}_{3}$ nanoparticles, a scan rate of $50.0 \mathrm{mV} \mathrm{s}^{-1}$ and a modulation amplitude of $0.3 \mathrm{~V}$. Fig $9 \mathrm{a}$ shows the differential pulse voltammograms obtained for the oxidation of different PTX concentrations at the PTN/CPE. Additionally, Fig. 9b exhibits clearly that the plot of oxidation peak current versus PTX concentration is constituted of three linear segments, corresponding to three different ranges of analyte concentration. From the data, detection limit $(3 \sigma)$ of PTX was obtained $2.1 \mathrm{nM}$ and linear range estimated to be $0.02-220.0 \mu \mathrm{M}$. A low detection limit for PTX is indicating the nanostructured modified electrode is an appropriate sensor for determination of PTX with high sensitivity. Therefore, the nanostructured electrode is a potential sensor for trace analysis of PTX in real samples.

\section{Interference study}

The selectivity of the PTN/CPE was evaluated in the presence of various interfering molecules. The tolerance limit of DPV studies was measured as the maximum concentration of the interference which caused an about $\pm 5 \%$ relative error in the analysis. The differential pulse voltammetric responses of PTX were studied in the presence of several possible interfering substances like $\mathrm{Na}^{+}, \mathrm{K}^{+}, \mathrm{NH}_{4}{ }^{+}, \mathrm{Zn}^{2+}$, $\mathrm{Cl}^{-}, \mathrm{CO}_{3}{ }^{2-}, \mathrm{SO}_{4}{ }^{2-}$, citric acid, lactic acid, dextrose, glucose, sucrose, starch, oxalic acid, glycine, L-phenyl alanine, uric acid, and dopamine. These substances may present in biological fluids and can interfere in the detection of PTX with conventional methods. The experiments showed that the molecules did not significantly influence on the oxidation peak current of PTX. The results are listed in Table 1.

\section{The repeatability and stability}

The electrode ability for the generation of a reproducible surface was studied by DPV obtained from five prepared PTN/CPEs. The calculated relative standard deviation for various factors accepted as the criteria for a satisfactory surface reproducibility (1.2-3.8\%). Furthermore, the longterm stability of the nanostructured modified electrode was evaluated over a 2-week period (Fig. 10). Differential pulse voltammograms recorded in the period showed the peak potential for PTX was unchanged and the current signals reduced only less than $2.1 \%$. These results indicate that the repeatability and stability of the nanostructured electrode are acceptable.

\section{Application of the method in real sample analysis}

For evaluation the applicability of the method, detection of PTX in industrial wastewater and biological samples (human blood plasma) was performed by standard addition method. The recovery percentages of the method were obtained between 94.0 and $104.7 \%$ and $96.5-106.0 \%$ for industrial wastewater and biological samples, respectively. The results are listed in Table 2. According to the results, very good recoveries were obtained for the detection of PTX, which indicates that the nanostructured sensor can be applied for the analysis of the analyte in environmental and biological samples. 
Fig. 9 a Differential pulse voltammograms of different concentrations of PTX at the surface of PTN/CPE and $\mathbf{b}$ plots of peak current as a function of PTX concentration

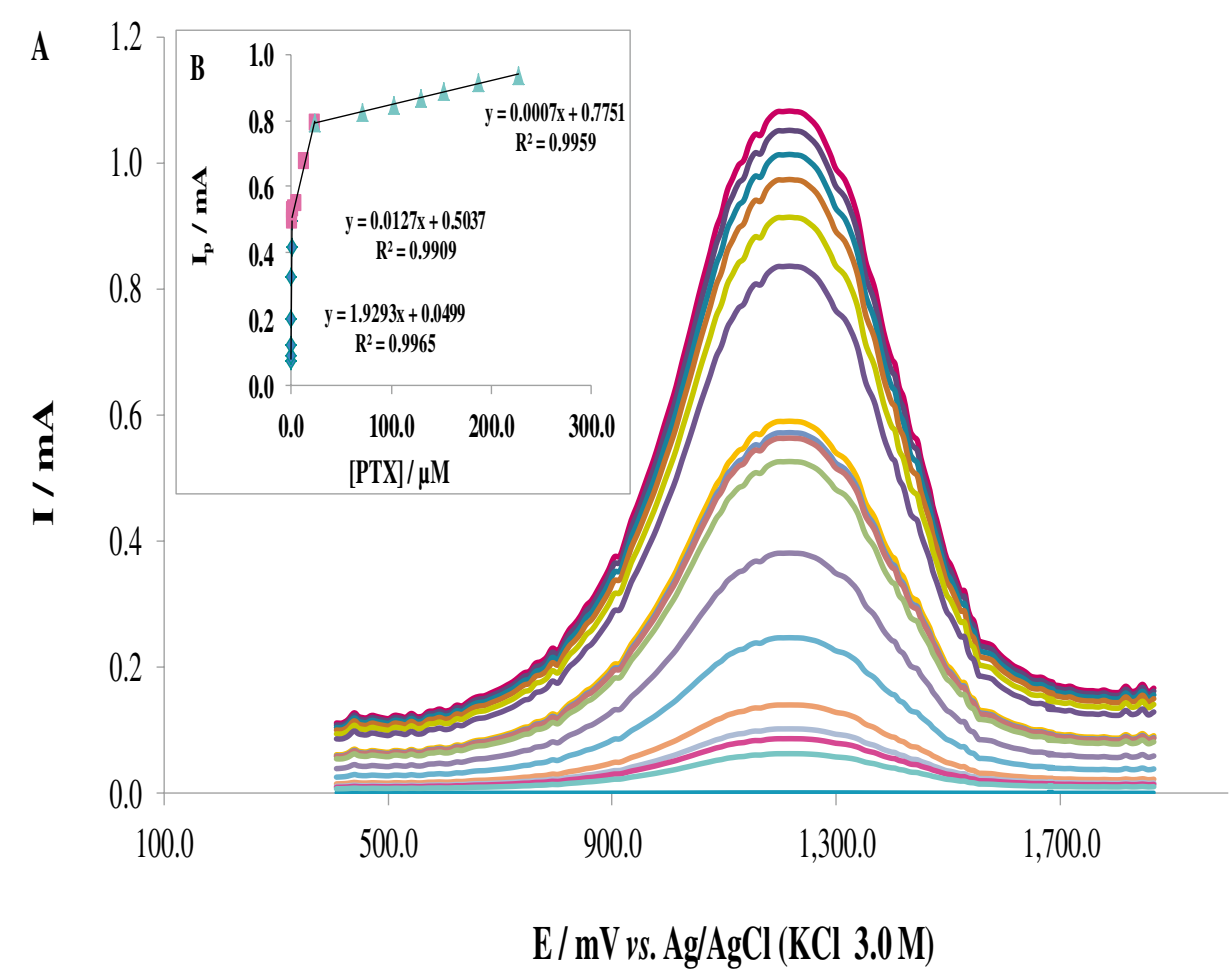

Table 1 Influence of some foreign substances on the determination of PTX at the surface of PTN/CPE

\begin{tabular}{ll}
\hline Foreign substances & $\begin{array}{l}\text { Tolerance limit } \\
\left(W_{\text {Substance }} / W_{\text {PTX }}\right)\end{array}$ \\
\hline $\mathrm{NH}_{4}{ }^{+}, \mathrm{Cl}^{-}$ & 600 \\
$\mathrm{Zn}^{2+}, \mathrm{SO}_{4}{ }^{2-}$ & 500 \\
$\mathrm{Na}^{+}, \mathrm{CO}_{3}{ }^{2-}$, oxalic acid & 400 \\
$\mathrm{Glycine}^{+}$ & 300 \\
$\mathrm{~K}^{+}, \mathrm{Cl}^{-}$, uric Acid & 200 \\
L-phenyl alanine & 100 \\
Dopamine, citric acid, lactic acid, dextrose, glu- & 20 \\
$\quad$ cose, sucrose, starch & \\
\hline
\end{tabular}

\section{Conclusions}

In the present study, $\mathrm{PbTiO}_{3}$ nanostructures were synthesized by a sol-gel method using citric acid as complexing agent. The structural and microscopic studies were performed using XRD and SEM techniques. Then, the synthesized nanopowders were used for designing a novel $\mathrm{PbTiO}_{3}$ nanostructures modified carbon paste electrode and its application for the determination of PTX. Characterization mechanisms showed the $\mathrm{PbTiO}_{3}$ nanopowders and nanostructured modified electrode were actually formed. The PTN/CPEs exhibited highly catalytic effect

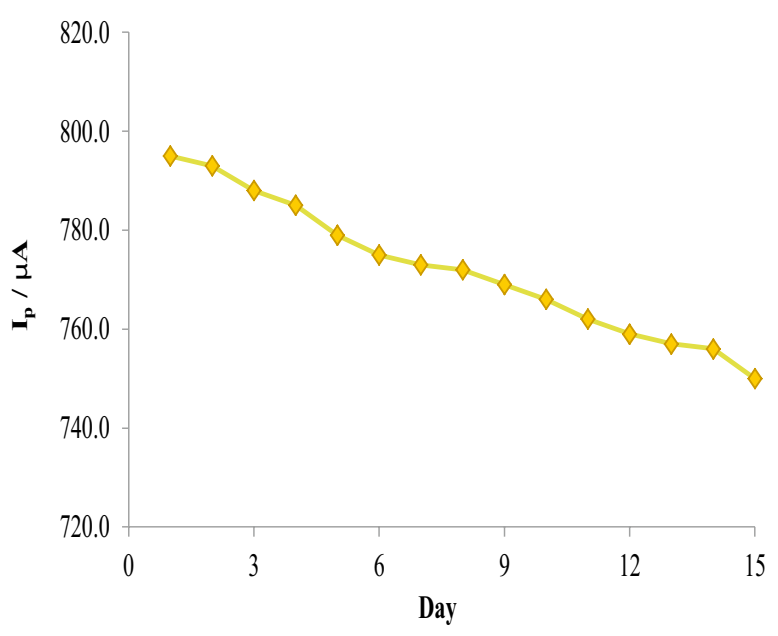

Fig. 10 Plot of stability of the PTN/CPE in $0.2 \mathrm{M} \mathrm{B-R}$ buffer (pH 7.5) for a 2-week period

to the oxidations of the analyte. The modified electrode showed high sensitivity in voltammetric measurements of PTX. Additionally, the nanostructured sensor exhibited good repeatability and stability for determination of PTX. Additionally, the nanostructures electrode was successfully used for the analysis of PTX in real complicated samples. 
Table 2 Determination of PTX in wastewater and human blood plasma samples

\begin{tabular}{lcll}
\hline Sample & Added $\left(\mu \mathrm{g} \mathrm{L}^{-1}\right)$ & Found $\left(\mu \mathrm{g} \mathrm{L}^{-1}\right)$ & Recovery $(\%)$ \\
\hline Wastewater & 0.0 & 4.9 & - \\
& 10.0 & 15.6 & 104.7 \\
& 20.0 & 23.8 & 95.6 \\
& 30.0 & 32.8 & 94.0 \\
Plasma & 0.0 & Not detected & - \\
& 10.0 & 10.6 & 106.0 \\
& 20.0 & 19.3 & 96.5 \\
& 30.0 & 31.4 & 104.7 \\
\hline
\end{tabular}

Acknowledgements We are grateful to Payame Noor University (Delijan, Iran) and University of Kashan (Kashan, Iran) for supporting this work.

Open Access This article is distributed under the terms of the Creative Commons Attribution 4.0 International License (http://creativeco mmons.org/licenses/by/4.0/), which permits unrestricted use, distribution, and reproduction in any medium, provided you give appropriate credit to the original author(s) and the source, provide a link to the Creative Commons license, and indicate if changes were made.

\section{References}

1. Wang, J., Xu, J., Goodman, M.D., Chen, Y., Cai, M., Shinar, J., Lin, Z.Q.: A simple biphasic route to water soluble dithiocarbamate functionalized quantum dots. J. Mater. Chem. 18, 3270-3274 (2008)

2. Nafari, A., Bowland, C.C., Sodano, H.A.: Ultra-long vertically aligned lead titanate nanowire arrays for energy harvesting in extreme environments. Nano Energy 31, 168-173 (2017)

3. Wang, J., Pang, X., Akinc, M., Lin, Z.: Synthesis and characterization of perovskite $\mathrm{PbTiO}_{3}$ nanoparticles with solution processability. J. Mater. Chem. 20, 5945-5949 (2010)

4. Shimada, T., Xu, T., Uratani, Y., Wang, J., Kitamura, T.: Unusual multiferroic phase transitions in $\mathrm{PbTiO}_{3}$ nanowires. Nano Lett. 16, 6774-6779 (2016)

5. Shimada, T., Xu, T., Araki, Y., Wang, J., Kitamura, T.: Multiferroic dislocations in ferroelectric $\mathrm{PbTiO}_{3}$. Nano Lett. 17, 2674 2680 (2017)

6. Wang, G.Z., Saeterli, R., Rorvik, P.M., Helvoort, A.T.J.V., Holmestad, R., Grande, T., Einarsrud, M.A.: Self-Assembled growth of $\mathrm{PbTiO}_{3}$ nanoparticles into microspheres and bur-like structures. Chem. Mater. 19, 2213-2221 (2007)

7. Selbach, S.M., Wang, G.Z., Einarsrud, M.A., Grande, T.: Decomposition and crystallization of a sol-gel-derived $\mathrm{PbTiO}_{3}$ precursor. J. Am. Ceram. Soc. 90, 2649-2652 (2007)

8. Hernandez-Sanchez, B.A., Chang, K.-S., Scancella, M.T., Burris, J.L., Kohli, S., Fisher, E.R., Dorhout, P.K.: Examination of sizeinduced ferroelectric phase transitions in template synthesized $\mathrm{PbTiO}_{3}$ nanotubes and nanofibers. Chem. Mater. 17, 5909-5919 (2005)
9. Wang, Y.G., Xu, G., Yang, L.L., Ren, Z.H., Wei, X., Weng, W.J., Du, P.Y., Shen, G., Han, G.R.: Preparation of single-crystal $\mathrm{PbTiO}_{3}$ nanorods by phase transformation from $\mathrm{Pb}_{2} \mathrm{Ti}_{2} \mathrm{O}_{6}$ nanorods. J. Alloys Compd. 481, L27-L30 (2009)

10. Son, J.Y., Shin, Y.H., Ryu, S., Kim, H., Jang, H.M.: Dip-pen lithography of ferroelectric $\mathrm{PbTiO}_{3}$ nanodots. J. Am. Chem. Soc. 131, 14676-14678 (2009)

11. Wang, X., Zhuang, J., Peng, Q., Li, Y.D.: A general strategy for nanocrystal synthesis. Nature 437, 121-124 (2005)

12. Omanwar, S.K., Jaiswal, S.R., Bhatkar, V.B., Koparkar, K.A. Comparative study of nano-sized $\mathrm{Al}_{2} \mathrm{O}_{3}$ powder synthesized by sol-gel (citric and stearic acid) and aldo-keto gel method. Optik 158, 1248-1254 (2018)

13. Najafi, A., Golestani-Fard, F., Rezaie, H.R.: Sol-gel synthesis and characterization of B4C nanopowder. Ceram. Int. 44, 2138621394 (2018)

14. Tsvetkova, B.G., Pencheva, I.P., Peikov, P.T.: Simultaneous determination of pentoxifylline and its impurities in tablet dosage forms by RP-HPLC. Der Pharma Chemica 4, 608-612 (2012)

15. Told, R., Fuchsjäger-Mayrl, G., Wolzt, M., Popa-Cherecheanu, A., Schmetterer, L., Garhofer, G.: Interaction between leukocytes and erythrocytes in the human retina: effects of pentoxifylline on hyperoxia-induced vasoconstriction during increased neutrophil counts. Microvasc. Res. 92, 85-90 (2014)

16. Unal, C., Sen, C., Iscen, D., Dalcic, H.: In vivo observation of leukocyte-endothelium interaction in ischemia reperfusion injury with the dorsal window chamber and the effects of pentoxifylline on reperfusion injury. J. Surg. Res. 138, 259-266 (2007)

17. Martos-Fernández, M., Saez-Barba, M., López-López, J., EstrugoDevesa, A., María Balibrea-del-Castillo, J., Bescós-Atín, C.: Pentoxifylline, tocopherol, and clodronate for the treatment of mandibular osteoradionecrosis: a systematic review. Oral Surg. Oral Med. Oral Pathol. Oral Radiol. Endod. 125, 431-439 (2018)

18. Tsvetkova, B.G., Pencheva, I.P., Peikov, P.T.: Simultaneous determination of pentoxifylline and its impurities in tablet dosage forms by RP-HPLC. Der Pharma Chemica 4, 608-612 (2012)

19. Saša, B., Odon, P., Stane, S., Julijana, K.: Analysis of surface properties of cellulose ethers and drug release from their matrix tablets. Eur. J. Pharm. Sci. 27, 375-383 (2006)

20. Grozdanovic, O., Antic, D., Agbada, D.: Development of a HPTLC method for in-process purity testing of pentoxifylline. J. Sep. Sci. 28, 575-580 (2005)

21. Abbar, J., Malode, S., Nandibewoor, S.: Electrochemical determination of a hemorheologic drug, pentoxifylline at a multi-walled carbon nanotube paste electrode. Bioelectrochemistry 83, 1-7 (2012)

22. Khoobi, A., Ghoreishi, S.M., Behpour, M., Shaterian, M., Salavati-Niasari, M.: Design and evaluation of a highly sensitive nanostructure-based surface modification of glassy carbon electrode for electrochemical studies of hydroxychloroquine in the presence of acetaminophen. Colloids Surf. B 123, 648-656 (2014)

23. Zare, K., Sadjadi, M.S., Enhessari, M., Khanahmadzadeh, S.: Synthesis and characterization of $\mathrm{PbTiO}_{3}$ nanopowders by citric acid gel method. J. Phys. Theor. Chem. 6, 9-12 (2009)

Publisher's Note Springer Nature remains neutral with regard to jurisdictional claims in published maps and institutional affiliations. 


\section{Affiliations}

\section{Asma Khoobi ${ }^{1,2} \cdot$ Abdol Mohammad Attaran $^{2} \cdot$ Masoud Yousofi $^{2} \cdot$ Morteza Enhessari $^{3}$}

1 Department of Analytical Chemistry, Faculty of Chemistry, University of Kashan, P.O. Box. 87317-51167, Kashan, Islamic Republic of Iran

2 Department of Chemistry, Payame Noor University, Delijan, Iran
3 Department of Chemistry, Naragh Branch, Islamic Azad University, Naragh, Islamic Republic of Iran 